\title{
C-Type Lectin Receptors in Asthma
}

\author{
Sabelo Hadebe ${ }^{1,2 *}$, Frank Brombacher ${ }^{1,2}$ and Gordon D. Brown ${ }^{3,4}$ \\ 'Division of Immunology and South African Medical Research Council (SAMRC), Immunology of Infectious Diseases, Faculty \\ of Health Sciences, Institute of Infectious Diseases and Molecular Medicine (IDM), University of Cape Town, Cape Town, \\ South Africa, ${ }^{2}$ International Centre for Genetic Engineering and Biotechnology, Cape Town Component, Cape Town, South \\ Africa, ${ }^{3}$ Medical Research Council Centre for Medical Mycology at the University of Aberdeen, Aberdeen Fungal Group, \\ Institute of Medical Sciences, Aberdeen, United Kingdom, ${ }^{4}$ Division of Medical Microbiology, Faculty of Health Sciences, \\ Institute of Infectious Diseases and Molecular Medicine (IDM), University of Aberdeen AFGrica Unit, University of Cape Town, \\ Cape Town, South Africa
}

\section{OPEN ACCESS}

Edited by:

Roland Lang,

Universitätsklinikum Erlangen, Germany

Reviewed by: Taruna Madan, National Institute for Research in Reproductive Health (ICMR), India

Clarissa Prazeres Da Costa, Technische Universität München,

Germany

${ }^{*}$ Correspondence:

Sabelo Hadebe sabelo.hadebe@uct.ac.za

Specialty section:

This article was submitted to Molecular Innate Immunity, a section of the journal Frontiers in Immunology

Received: 20 November 2017 Accepted: 23 March 2018 Published: 11 April 2018

Citation: Hadebe S, Brombacher F and Brown GD (2018) C-Type Lectin Receptors in Asthma. Front. Immunol. 9:733. doi: 10.3389/fimmu.2018.00733
Asthma is a heterogeneous disease that affects approximately 300 million people worldwide, largely in developed countries. The etiology of the disease is poorly understood, but is likely to involve specific innate and adaptive responses to inhaled microbial components that are found in allergens. Fungal-derived allergens represent a major contributing factor in the initiation, persistence, exacerbation, and severity of allergic asthma. C-type lectin like receptors, such as dectin-1, dectin-2, DC-specific intercellular adhesion molecule 3-grabbing nonintegrin, and mannose receptor, recognize many fungal-derived allergens and other structurally similar allergens derived from house dust mites (HDM). In some cases, the fungal derived allergens have been structurally and functionally identified alongside their respective receptors in both humans and mice. In this review, we discuss recent understanding on how selected fungal and HDM derived allergens as well as their known or unknown receptors shape allergic airway diseases.

Keywords: C-type lectin receptors, allergens, dectin-1, fungi, sensitization

\section{INTRODUCTION}

Over the past few decades, it has become widely accepted that fungi can contribute negatively to many aspects of human health and the particular focus on this review is allergic airway diseases. Two-thirds of asthmatics display an atopic response to multiple allergens, with at least $6-8 \%$ of the world's population suffering due to exposure to mold and other microbial components $(1,2)$. Fungal sensitization plays a role in patients with respiratory allergic disease through initiation, persistence, and exacerbation of allergic asthma. There is a correlation in the number of patients sensitized to fungi and the severity of asthma (3). The exact estimate of the prevalence of fungal sensitization among asthma patients is unclear, partly because exposure is universal, variable in time and intensity (4).

Asthmatics can be sensitized to multiple fungal species, and early exposure in the first 3 months of life has been associated with increased risk of developing asthma in children (5). The most common fungal species associated with sensitization, include Alternaria alternata, Penicilium spp., Cladosporium spp., Aspergillus spp., and C. albicans (6). Sensitization to fungi occurs everywhere, both indoors and outdoors, and this is linked to asthma exacerbations (7). Allergic bronchopulmonary aspergillosis (ABPA) is a disease caused by bronchial colonization with Aspergillus spp. and it affects approximately $0.7-3.5 \%$ of asthmatics (2). The disease features closely resemble those of severe asthmatics sensitized to fungi and both groups of patients have significantly better outcomes if treated with antifungals, such as itraconazole and voriconazole $(3,8,9)$. In a study conducted in North India, the prevalence of ABPA and fungal hypersensitivity among acute asthma patients was estimated at 38.6 and $50.9 \%$, respectively, and the overlap between diseases was estimated at $75.9 \%$ using a skin prick test (10). 
TABLE 1 | Common allergens found in fungi and house dust mites (HDM) and their binding receptors.

\begin{tabular}{|c|c|c|c|c|}
\hline Allergen & Source & Receptor & Localization & Reference \\
\hline$\beta$-glucan & $\begin{array}{l}\text { HDM } \\
\text { A. fumigatus } \\
\text { A. versicolor } \\
\text { C. cladosporioides }\end{array}$ & Dectin-1 & $\begin{array}{l}\text { Macrophage, monocytes, subsets of DCs, epithelium, } \\
\text { basophils }\end{array}$ & $(108,117,118)$ \\
\hline$\alpha$-mannans & $\begin{array}{l}\text { HDM } \\
\text { A. fumigatus } \\
\text { C. neoformans }\end{array}$ & Dectin-2 & Macrophage, monocytes, subsets of DCs, basophils & $(46,48,53-55)$ \\
\hline $\begin{array}{l}\text { Derp-1 } \\
\text { Derp-2 } \\
\text { BG-60 }\end{array}$ & $\begin{array}{l}\text { HDM } \\
\text { HDM }\end{array}$ & $\begin{array}{l}\text { DC-specific intercellular adhesion molecule } \\
\text { 3-grabbing nonintegrin }\end{array}$ & Monocyte-derived DCs & $(63-65)$ \\
\hline $\begin{array}{l}\text { Derp-1 } \\
\text { Derp-2 }\end{array}$ & $\begin{array}{l}\text { HDM } \\
\text { HDM } \\
\text { Cockroach }\end{array}$ & Mannose receptor & DCs, macrophages & $(76,77)$ \\
\hline $\begin{array}{l}\text { Derp-1 } \\
\text { Derf-1 } \\
\text { Glycoprotein } 55 \\
\text { and } 45\end{array}$ & $\begin{array}{l}\text { HDM } \\
\text { HDM } \\
\text { A. fumigatus }\end{array}$ & Surfactant protein $A$ and $D$ & Alveolar type II cells & $(84,125)$ \\
\hline Chitin & $\begin{array}{l}\text { HDM } \\
\text { A. fumigatus }\end{array}$ & $\begin{array}{l}\text { Mannose receptor, dectin-1/TLR-2, NOD, } \\
\text { Regllly, FIBCD1 }\end{array}$ & FIBCD1 (gut enterocytes), Regllly (gut epithelium) & $(30,33,36,39)$ \\
\hline
\end{tabular}

Allergic bronchopulmonary aspergillosis is characterized by a Th2 cell infiltrate, increased pulmonary and blood eosinophilia, brownish black mucus plugs, total serum IgE levels over $1,000 \mathrm{ng} / \mathrm{mL}$ (416 IU/mL), Aspergillus-specific IgE and IgG1 antibodies (3). These characteristics are similar to allergic asthmatics sensitized to various allergens such as those derived from house dust mites (HDM), pollen, cockroach, etc. In fact many fungal sensitized asthmatics can be misdiagnosed as having ABPA with further tests usually required to rule out $\operatorname{ABPA}(2,11)$. A considerable difference in fungal sensitized asthmatics is that they do not show signs of bronchial colonization by A. fumigatus and are immunologically sensitized to more than one fungal species, such as $A$. alternata, $P$. notatum, $C$. herbarum, A. fumigatus, $A$. niger, and C. albicans (3). Other useful methods for identifying ABPA, include computed tomography scan, chest radiographic lesions, and plasma levels of CCL17 which in combination with other criteria can help to stratify patients (12). This shows an overlap in clinical diagnosis, treatment, and fungal spores responsible for initiating these diseases (11). Fungal spores are diverse, and ubiquitous in our environment, making it difficult to estimate an average number of spores humans inhale per day $(13,14)$.

The majority of fungal spores in outdoor environments belong to the phylum Ascomycota and Basidiomycota (2). Most fungi contain multiple and variable allergens derived from conidia, spores, hyphae, or hyphal fragments and these are easily inhalable and likely to be the causal factors in allergic asthma. Some of these allergens are released during lysis/breakdown of fungal spore/hyphae and some are secreted by the fungus (14). Although protease allergens from fungi represent a larger proportion and are the most studied of the fungal allergens, other molecules, which are part of the fungal cell wall like chitin, mannans, and $\beta$-glucans, represent an important group of fungal allergens (Table 1). In recent years, there has been a huge effort in understanding what host-factors recognize fungal species and how the immune response to these fungal patterns is initiated and intricately regulated. C-type lectins were discovered as major fungal recognition receptors and shown to play critical roles in innate immunity and directing adaptive responses. The focus of this review is to highlight how fungal-derived allergens and their respective receptors (mainly, but not limited to C-type lectins) shape asthma.

\section{C-TYPE LECTIN RECEPTORS}

C-type lectin-like receptors (CLRs) are carbohydrate, lipid, or protein binding proteins, identified by the unique structure of at least one C-type lectin-like domain (CTLD). The CLRs family of proteins is made of more than 1,000 members, organized into 17 groups with diverse functions, including cell adhesion, phagocytosis, complement activation, innate immunity, and others (15). CLRs recognize non-self, microbial pattern-associated molecular patterns (PAMPs) on surface of fungi, bacteria, viruses, parasites, and house dust mite allergens $(16,17)$. They can also recognize damaged self-antigens, damage-associated molecular patterns or tumor antigens, tumor-associated molecular patterns (16). CLRs mostly recognize extracellular ligands, but some have been reported to recognize endogenous intracellular ligands, for example, DNGR-1 senses F-actin (18). The recognition occurs through their extracellular structurally conserved CTLD and is tightly regulated by specific amino acid motifs, calcium ions, and the carbohydrate structure. Once engaged with their respective ligands they induce intracellular signal pathways coupled to spleen tyrosine kinase (Syk). Downstream, Syk phosphorylates a number of substrates, such as protein kinase c-delta (PKC- $\delta$ ), which in turn phosphorylates CARD-9 resulting in the formation of a complex made up of CARD-9, Malt-1, Bcl10 (19-22). This leads to activation of NF-kB and induction of inflammatory responses including activation of anti-microbial responses 
and cytokine production that direct both innate and adaptive responses $(19,23)$. Some Syk coupled CLRs possess an intracellular immunoreceptor tyrosine-based activation motifs (ITAM) on their signaling tail that acts as an adaptor which recruits and activates Syk (24). Other pathways that do not involve ITAMs have been reported to trigger Raf-1 activation via receptors such as DC-specific intercellular adhesion molecule 3-grabbing nonintegrin (DC-SIGN) and dectin-1. Some Syk coupled CLRs lack the intracellular signaling tail and rely on ITAM coupled $\mathrm{FcR} \gamma$ adaptors for engagement with Syk. CLRs can be classified according to their ability to interact and signal directly with Syk (cluster 1) or requirement for adaptor molecule $\mathrm{FcR} \gamma$ (cluster 2). Cluster 1 mainly consists of dectin-1-like CLRs, such as Clec-2 and DNGR1, and the second cluster mainly consists of dectin2-like CLRs, such as MCL and Mincle (25). Not all CLRs are activating upon ligand binding and some CLRs have an integral immunoreceptor tyrosine-based inhibitory motif (ITIM) on their cytoplasmic tail, such as MICL (26).

\section{Chitin Detecting CLRs}

Chitin, a polymer of $\beta$-(1-4)-poly- $N$-acetyl-D-glucosamine repeating units is found in various organisms, including fungi, arthropods, helminth parasites, and mites. In fungi, chitin constitutes about $2 \%$ of the fungal cell wall dry weight, and forms part of the cell wall inner layer giving it its rigidity (27). How chitin is sensed by the host immune cells remains controversial and unresolved (28). To date the only chitin vertebrate-specific receptor identified is FIBCD1, a $55 \mathrm{kDa}$ homotetrameric type II transmembrane protein expressed in gut enterocytes (29). Chitin sensing has been speculated to involve engagement of multiple PRRs, including TLR-2, dectin-1, TLR-9, NOD receptor, mannose receptor, and soluble C-type lectin RegIII $\gamma$, in a polymer size, concentration, and acetylation status-dependent manner (30-32). Smaller chitin fragments $(1-10 \mu \mathrm{m})$ promote anti-inflammatory IL-10 production in a MR-, NOD-, and TLR9dependent manner, whereas intermediate fragments $(40-70 \mu \mathrm{m})$ promote pro-inflammatory cytokine TNF- $\alpha$ in a dectin-1/TLR-2 manner both in vitro and in vivo $(31,32)$. Larger ones $(50-100 \mu \mathrm{m})$ promote eosinophilic inflammation and alternatively activated macrophages in vivo (33-35). However, difficulties in purifying high quality chitin and mannan contaminated commercial chitin have left some speculations on whether contaminants could be partly responsible for multiple PRR engagement. Aspergillus fumigatus and crustacean-derived chitin was shown to initiate innate allergic responses by recruiting IL-4 positive immune cells, such as eosinophils and basophils $(33,35,36)$. Chitin was shown to activate ILC2s by inducing IL-33, IL-25, and TSLP production by the epithelial cells (33). It was further shown that chitin induced alternative-activated macrophages (AAMs, M2) and eosinophilia an ILC2-dependent manner. Lack of IL-25, TSLP, and IL-33 resulted in normal lung ILC2 accumulation, but reduced secretion of IL-5 and IL-13 which lead to reduced AAM and eosinophilia (33). The role of chitin in Th2-mediated airway inflammation was also supported by another study that showed that chitin induced CCL2 production by epithelial cells, which in turn activated AAMs and eosinophilia in a CCR2dependent manner (37). Mice constitutively overexpressing acidic mammalian chitinase (AMCase) (SPAM mice) in the lung, when challenged with chitin or A. fumigatus had attenuated eosinophilia, AAMs, and Th2-associated cytokines (33, $35,36,38)$. In addition, AMCase enzyme dead knock-in mice (AMCase-ED) or AMCase knock-in/knock-out (ChiaRed) mice are unable to clear chitin polymers and have heightened Th2 type and pro-fibrotic lung inflammation at steady state or when exposed to medium or large chitin particles, crude HDM (large particles chitin content) or filtered HDM (small particle chitin content) $(38,39)$. However, AMCase-deficient mice have given contradictory reports compared to AMCase-ED or ChiaRed mice $(38,39)$. AMCase-deficient mice did not show aberrant type 2 responses during ovalbumin or HDM-induced allergic asthma $(40,41)$. These contrasting findings between these mice remain to be reconciled by direct comparison of the strains. One key difference between the two strains is that AMCase-ED and ChiaRed mice are able to express AMCase protein which is capable of binding chitin, however, the chitinase activity is diminished $(38,39)$.

Much remains to be learnt about the mechanisms involved in chitin recognition and clearance. Currently, it is unclear whether the PRRs that have been implicated in recognition of small and medium sized chitin polymers to induce IL-10 and TNF- $\alpha$ will be the same receptors inducing Th2 type allergic asthma. None of the receptors identified so far as chitin recognition receptors which are specific to chitin apart from FIBCD1. FIBCD1 seems to be expressed specifically in the stomach and not lung tissue. Perhaps the role of this receptor as a chitin-specific receptor will become clearer once FIBCD1-deficient mice become available. In humans, an AMCase single nucleotide polymorphism exists displaying hyper chitinase activity (42). This AMCase isoform is common among American ethnic groups and has been associated with protection against asthma (42).

\section{Dectin-2}

Dectin-2 is a $28 \mathrm{kDa}$, type II transmembrane CTLR, containing a single extracellular CTLD connected by a neck region to its short cytoplasmic tail (43). Dectin-2 recognizes high mannose structures on the surfaces of a wide range of microbes and has also been shown to have a putative endogenous ligand on CD4 T cells $(44,45)$. Moreover, dectin- 2 recognizes $\alpha$-mannans in many species of fungi, including C. albicans, Paraccoides brasiliensis, Histoplasma capsulatum, and Cryptococcus neoformans $(46,47)$. Apart from fungal ligands, dectin-2 has also been shown to recognized HDM allergen (Dermatophagoides farinae and D. pteronyssinus) (48), although the exact nature of ligands have not been elucidated.

Dectin-2 has no obvious signaling motif on its short cytoplasmic tail and relies on the ITAM-bearing $\mathrm{FcR} \gamma$ chain for signal transduction and downstream effects, including NFkB activation, Syk recruitment, and cytokine production $(45,49)$. The FcR $\gamma$ chain and its phosphorylation by Src kinases were shown to be important for the surface expression of dectin-2 and the subsequent downstream signals $(45,49)$.

In C. albicans, mice deficient in dectin-2 are susceptible to systemic infections and fail to mount Th17 responses critical for fungal clearance $(45,47,50)$. In the cases of allergic asthma induced by $D$. farinae mites, dectin-2 was shown to be activated 
by a yet unidentified ligand $(51,52)$. Dectin- 2 activation during the sensitization stage in DCs triggers generation of cysteinyl leukotrienes, pro-inflammatory lipid mediators, Th2 cytokines, in a FcR $\gamma$-, Syk-, and CARD-9-dependent manner (51, 53). Blocking of dectin-2 with antibody during the HDM challenge stages showed a redundant role of the receptor in airway inflammation and AHR (54). In contrast, antibody-mediated blockage of dectin-2 and dectin-2-deficient mice sensitized with wild type D. furinae-pulsed DCs had attenuated pulmonary inflammation (55). Moreover, dectin-2 deficiency had little effect on Th2 cytokine production by lung-draining MLN and systemic IgE and IgG1 production, suggesting that dectin- 2 mediates localized Th 2 responses during the effector phase $(54,55)$. Indeed, the mechanisms of dectin-2/HDM-induced Th2 allergic airway responses has been shown to require FcR $\gamma$-dependent type 2 alarmin IL-33 secretion and its autocrine signaling receptor ST2, which is thought to promote lung DCs maturation (56). Recently, phosphorytidylinositol 3 kinase delta (PI3K $\delta$ ) signaling pathway was also shown to be required for the dectin-2/FcR $\gamma$-dependent cysteine leukotriene production and Th 2 and Th17 allergic airway responses induced by $D$. furinae (57). Inhibition of PI3K $\delta$ ameliorated HDM-induced allergic asthma, suggesting a targetable pathway in the treatment of asthma. Interestingly, PBMCs from asthmatic patients were shown to upregulate expression of dectin-2, suggesting an important role for this receptor in human disease (54). Despite dectin-2 being shown to be important in antifungal immunity and in asthma in mouse models, no single mutation associated with disease has been observed so far in humans.

\section{DC-Specific Intercellular Adhesion Molecule 3-Grabbing Nonintegrin}

DC-specific intercellular adhesion molecule 3-grabbing nonintegrin is a $44 \mathrm{kDa}$ type II transmembrane protein receptor (58). DC-SIGN is arranged as a tetramer of autonomous CTLD that interact through alpha helix neck domain (59). It consists of an extracellular domain that contains a CRD arranged in a homodimeric cluster, a hinged domain followed by a transmembrane region and a cytoplasmic domain/signaling tail (Figure 1). The CRD recognizes a broad spectrum of mannose and fucose ligands

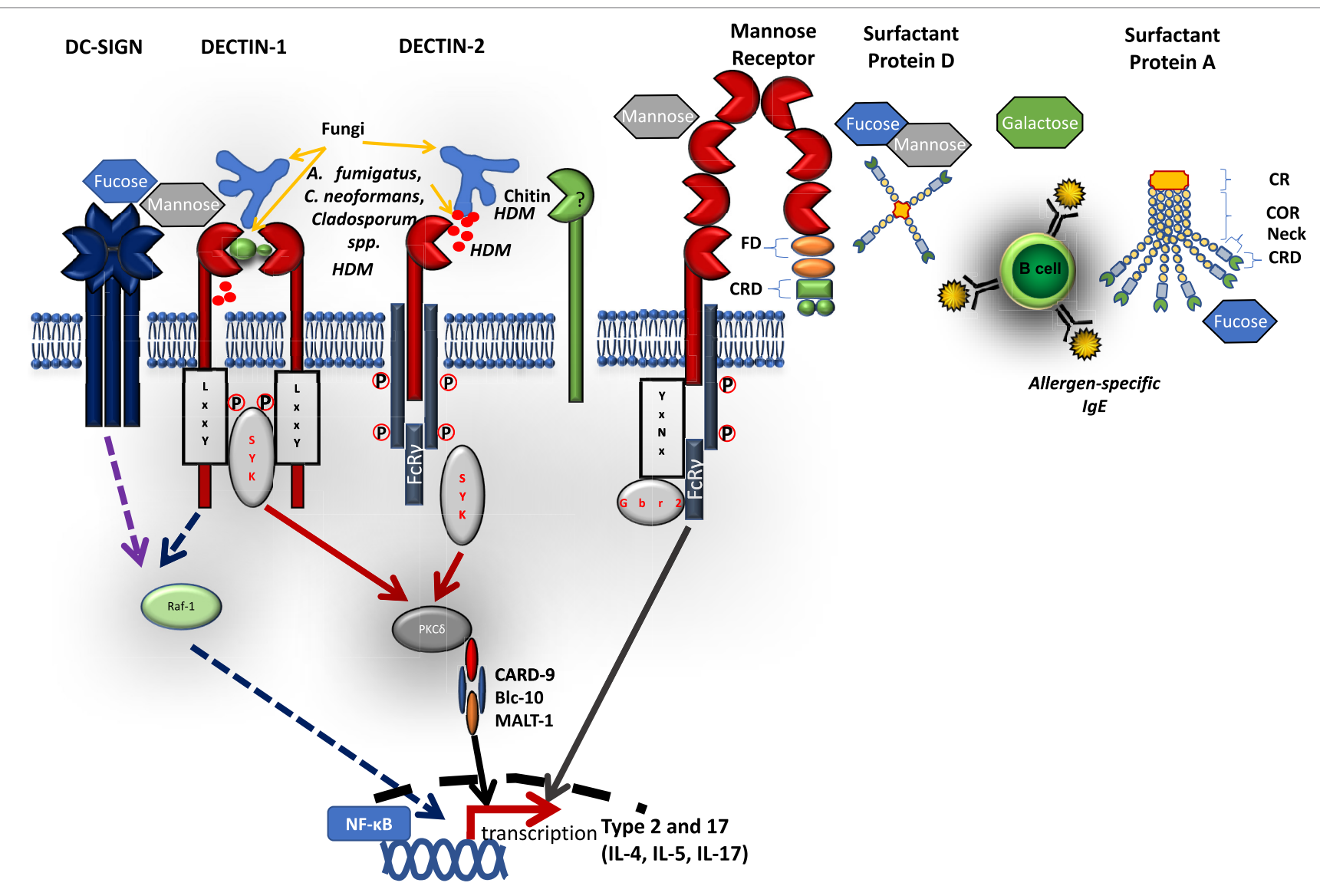

FIGURE 1 | Schematic diagram of selected C-type lectin-like receptors (CLRs) and their respective ligands. C-type lectin receptors bind to their respective extracellular microbial pattern-associated molecular patterns on cell wall surfaces of fungi and house dust mites. Most CLRs signal via a Syk-dependent pathway inducing reactive oxygen species, inflammatory cytokines, and antimicrobial peptides. Some CLRs, e.g., dectin-1 and DC-specific intercellular adhesion molecule 3-grabbing nonintegrin can signal via a Syk-independent pathway involving Raf-1. Some CLRs (such as dectin-2 and MR) cannot directly activate Syk, but require adaptor protein FcR $\gamma$ attached to its intracellular immunoreceptor tyrosine-based activation motifs. Soluble CLRs, such as surfactant proteins (SP-A, SP-D) are arranged in either one or two polypeptide chains with a CRD connected to neck region, a collagen-rich domain, and cytoplasmic region. FD, fibronectin domain; CRD, carbohydrate recognition domain; COR, collagen-rich domain. 
on various microbes, including viruses (HIV gp120 glycoprotein, measles viruses), parasites (Leshmania spp., S. mansoni), fungi (C. albicans), bacteria (Helicobacter pylori, M. tuberculosis, and M. leprae), and self-ligands, such as, ICAM-2, ICAM-3, and Mac-1 $(58,60)$. The carbohydrate structure recognition by CRD seems to be $\mathrm{Ca}^{2+}$-dependent. Because of its broad specificity to sugar moieties, DC-SIGN has been shown to be an exploitable target for many pathogens as they use it to subvert host killing mechanisms $(58,59)$.

Although DC-SIGN lacks the consensus signaling motifs that interact with Syk kinases and other downstream adaptors, DC-SIGN still acts as a signaling receptor. Activation of DC-SIGN does not induce an immediate downstream signal, however, DC-SIGN has been shown to modulate signals initiated by toll-like receptors (61). Depending on the engaged ligand, e.g., fucose or mannose, the intracellular tail of DC-SIGN forms a ligand-specific signalomes with kinases including Raf- 1 . This enhances phosphorylation and acetylation of NFkB subunit p65 and heightened pro-inflammatory (Th1) or suppression of NFkB activation and induction of anti-inflammatory (IL-10 and Th2) gene transcription $(61,62)$.

Allergens containing protease activity have been shown to have multiple mechanisms of generating allergic inflammation. The major peanut allergen (Ara $h 1$ ), grass pollen allergen (BG-60), major dog allergen (Can f 1), and major dust mite allergens (Derp-1 and Derp-2) have been shown to activate DC-SIGN, initiating cytokine production and allergic inflammation biased toward Th2 polarization (63-65).

Binding of glycosylated Derp-2 to DC-SIGN on human DCs elicits TNF- $\alpha$ release. Furthermore, in DC/T-cell co-culture experiments Derp-1 pre-treated monocyte-derived DC induced GATA3 and IL-4 expression by naive T cells (66). This is also supported by studies showing that Derp-1 stimulation of human DCs leads to downregulation of DC-SIGN and bias toward Th2 polarization $(63,66)$. Moreover, DCs from atopic asthmatics have reduced DC-SIGN expression which correlates with data demonstrating downregulation of DC-SIGN expression by Derp-1 during the differentiation of immature monocyte-derived DCs (66).

The mechanism for Th2 differentiation by protease/DC-SIGN engagement are not fully understood, but are thought to be due to the loss of DC-SIGN expression through cleavage. This leads to reduced binding to its ligand ICAM-3 on naive T cells, which is thought to be important in Th1 polarization (67). Although protease cleavage of DC-SIGN is the most studied mechanism for Th2 type response induction, other studies suggests that nonproteolytic mechanisms involving selective DC-SIGN activation by fucose ligands may direct Th2 cell differentiation (62). Fucose from pathogens, such as $H$. pylori and soluble egg antigen, from S. mansoni was recently shown to directly inhibit TLR-4-induced pro-inflammatory cytokine production associated with Th1 polarization and activated anti-inflammatory cytokine IL-10 and Th2-associated chemokines CCL17 and CCL22. This fucose triggering of DC-SIGN required an initial TLR-4 priming, Raf-1 activation, and displacement of the mannose signalome on the signaling tail of DC-SIGN. Downstream, Bcl3, an NFkB subunit interferes with p50-p65 subunit dimerization and binds to p65 binding site and translocate to the nucleus, thereby repressing NFkB-dependent transcription of pro-inflammatory genes (62). Whether this fucose/DC-SIGN signaling and Th2 differentiation is a common mechanism for all fucose decorated allergens such as those derived from fungi or HDM, and how DC-SIGN selectively engages different carbohydrate, is currently unclear and requires further investigation.

Studies on DC-SIGN function in vivo are limited as there are no murine orthologs, although several murine homologs, such as SIGNR3 and SIGNR5, exist with gene-deficient mice available (59). However, the marked differences in signaling pathways downstream of DC-SIGN and its supposed murine orthologs puts into question their validity in experimental models.

\section{Mannose Receptor}

Mannose Receptor was one of the first CLR to be discovered and was shown to be involved in the clearance of glycoproteins $(68,69)$. Mannose receptor is a $175 \mathrm{kDa}$ type I integral transmembrane glycoprotein that binds structures like L-fucose, D-mannose, or $\mathrm{N}$-acetylglucosamine through $\mathrm{Ca}^{2+}$-dependent mechanisms as well as structures, such as sulfated acidic glycans through the cysteine-rich domain (70). Like DC-SIGN, MR structure has 3 regions, a cysteine-rich domain, a fibronectin type II-like domain, and 8 CTLDs, followed by a transmembrane region and a hydrophilic internal cytoplasmic domain (Figure 1) $(68,70)$. The cytoplasmic domain participates in receptor internalization and recycling, whereas the fibronectin type II-like domain mediates collagen binding (68).

Mannose receptor has been shown to recognize a range of organisms, including C. albicans (71), P. carinni (72), HIV (gp120) (73), mycobacterium (74), Leishmania, and some bacterial species. MR has also been shown to bind endogenous self-antigens, including ligands in the $\mathrm{B}$ cell follicles in the spleen and thyroid $(68,75)$.

Although MR was one of the first studied CLR, its signaling pathways have been a matter of considerable interest, mainly because the cytoplasmic tail lacks an ITAM or ITIM motifs. The tyrosine residue on the 18th position of the MR cytoplasmic tail is thought to be important for receptor endocytosis (68). A recent study has identified the ITAM-bearing FcR $\gamma$ as a key adaptor in human MR signaling (74). Upon ligand, mannose capped lipoarabinomannan (ManLAM) engagement, MR cytoplasmic tail interacts with $\mathrm{FcR} \gamma$ which when phosphorylated recruits another adaptor Grb2. Gbr2 recognizes specific motif ( $\mathrm{YxNx}$ ) on MR cytoplasmic tail and activates another complex Rac-1, Cdc42, and PAK-1. The formation of this complex eventually promotes phagocytosis. Once in the phagosome, Grb2 complex recruits a tyrosine phosphatase SHP-1 which upon phosphorylation interacts directly with Grb2 complex. SHP-1 interrupts the formation of MR-dependent phagosome-lysosome fusion upon $M$. $t b$ infection and promotes $M$. $t b$ growth inside phagosomes.

Similar to DC-SIGN, MR binds to a number of carbohydrate microbial cell surface ligands, such as mannans and proteolytic allergens, including HDM allergens (Derp-1 and Derp-2), German cockroach allergen (Bla g 2), major dog allergen (Can f 1), cat allergen (Fel d 1), and major peanut allergen (Ara h 1) (76-78). DCs from atopic asthmatics have elevated MR expression 
and are efficient in uptake of Derp-1 HDM allergen compared to non-asthmatic controls (78). Furthermore, human MR-deficient DCs fail to induce a Th2 polarization in naive T cell/DC coculture when stimulated with Derp-1. Unlike DC-SIGN, MR activation by protease does not involve cleavage of the receptor, however, it is thought to involve direct recognition by the CTLD$4-7$ region $(76,77)$. This is further supported by studies demonstrating that human MR engagement with its ligand, Derp-1 initiates Th2 polarization through modulation of indoleamine 2,3-dioxygenase (IDO) activity, an immune modulator enzyme involved in tryptophan metabolism. In a mouse model using a cockroach allergen-induced allergic airway response, MR was shown to be important in allergen uptake and in regulation of Th2 allergic airway inflammation, as mice deficient of MR showed aberrant Th2 responses (79). Mechanistically, MR together with its intronic microRNA (miR-55-3p) was shown to regulate macrophage polarization from M2 to M1 upon cockroach allergen stimulation, resulting in protection against allergen-induced allergic airway inflammation in vivo (79). Currently, most of what we know about MR in allergic asthma has been done using human cells and knockdown approaches. Very little been done in vivo using known fungal derived ligands despite the fact that MR-deficient mice have been available for some time and can be a useful resource in understanding mechanisms of MR-mediated asthma (79). It is also important to note that there are considerable differences between mouse and human MR signaling, for example, SHP-1 is not robustly expressed in mice and does not interact with MR. Humanized mice expressing a human version of MR will bring into light some of the key regulatory roles of MR in allergic asthma.

\section{Surfactant Proteins A and D}

Lung surfactant proteins A and D (SP-A and SP-D) are soluble PRRs secreted mainly by alveolar type II cells (pneumocytes) and by other cells types, including non-ciliated bronchiolar cells, lung epithelial cells, and gastrointestinal and genitourinary tracts (80) SP-A and SP-D are part of the six human collectins described so far (80). They recognize sugar moiety patterns on the surface of various pathogens, including bacteria, fungi, and viruses with varying preference, i.e., SP-A preferentially binds monosaccharides, in contrast SP-D binds avidly to more complex saccharides (80). The structure of SP-A and SP-D is organized into four regions: an $\mathrm{N}$-terminal region (which forms interchain disulfide bonds), a collagen-rich region containing (Gly-Xaa-Yaa) repeats, a neck peptide and a C-terminal CRD (which interacts with carbohydrate structures) (80). SP-A has two $35 \mathrm{kDa}$ polypeptide chains (SP-A 1 and 2) arranged in a $635 \mathrm{kDa}$ hexamer, SP-D has one $43 \mathrm{kDa}$ polypeptide chain arranged in a tetramer of $520 \mathrm{kDa}$ (Figure 1) (80, 81).

SP-A and SP-D have been shown to bind to HDM allergen Derp-1 and glycoprotein allergens from A. fumigatus in a carbohydrate-specific and $\mathrm{Ca}^{2+}$-dependent manner $(82,83)$. This was shown to inhibit IgE binding to these glycoproteins, blocking allergen-induced histamine release from basophils and mast cells, and effectively reducing IgE hypersensitivity and allergic inflammation (84-86). SP-A and SP-D-deficient mice are inherently hypersensitive to pulmonary infections, showing increased eosinophilia and IL-13, a Th2-associated cytokine (86). The ability of SP-A and SP-D to block allergen-specific IgE and IgG1 can be explained by their potential to block B cell proliferation resulting in reduced antibody production. Another suggested mechanism is through production of IFN- $\gamma$ by CD4 T cells, which shifts cellular responses from Th2 to Th1 responses $(84,85)$. SP-A was recently shown to play an important role in local lung macrophage proliferation by boosting IL-4R $\alpha$ signaling, which was important for helminth expulsion (87). It is likely that similar mechanisms would exist for the induction of allergic asthma, but remain to be investigated. Genome-wide association studies have also linked single nucleotide polymorphisms in SP-A1 and SP-A2 gene to high susceptibility to ABPA, suggesting a key role of surfactants in fungal-induced asthma (88).

\section{Dectin-1}

Dectin-1 is a $28 \mathrm{kDa}$ type II membrane protein with a single extracellular lectin-like carbohydrate recognition domain connected by a stalk to the transmembrane region followed by a cytoplasmic signaling tail (Figure 1) (89). Dectin-1 was identified to be a major $\beta$ - $(1,3)$-D-glucan receptor in the early 2,000 through screening of mouse macrophage cDNA expression library with zymosan (a $\beta$-glucan-rich particle) (90). Other receptors have also been shown to bind $\beta$-(1,3)-D-glucan, including CR3, SCARF, lactosylceramide, CD36, and ephrin type-A receptor 2 (EphA2) (91, 92). $\beta$-(1,3)-D-glucan is a glucose polymer that is widely distributed across the biosphere predominantly found on the cell wall surfaces of plants (93) and fungi (such as Candida spp., Aspergillus spp., Coccidiodes spp., and Pneumocystis spp.) (90, 94-96). Dectin-1 has also been shown to bind an unidentified endogenous ligand in T cells (89).

Upon engagement with $\beta$-(1,3)-D-glucan, dectin- 1 initiates intracellular signals via its cytoplasmic ITAM-like motif through phosphorylation of a tyrosine residue residing within the YxxxL motif. Phosphorylation of the membrane proximal single tyrosine-based motif is sufficient to induce activation and recruitment of Syk and this type of sequence has been termed ITAM-like motif or HemITAM $(19,24,25)$. The hemITAM is thought to be important in dimerization of dectin-1 and the formation of a docking site for SH2 domains of Syk. Downstrean effects after Syk activation and recruitment are discussed above.

The wide distribution of $\beta$-(1,3)-D-glucans in nature and its importance in cell wall formation has brought considerable interests in its structure as a possible target for drug development or therapeutic potential. The $\beta$-(1,3)-D-glucan glucose polymer has variable molecular weight and degree of branching that can be triple helix, single helix, or random coil structured (97). In fungal cell wall, glucans compose about $40-50 \%$ of cell wall dry weight with at least $65-90 \%$ of the cell wall being $\beta-(1,3)$-D-glucans $(98)$. $\beta$ - $(1,3)$-D-glucans are covalently linked to $\beta$ - $(1,6)$-glucans and chitin $[\beta-(1,4)$-linked polymer of $N$-acetylglucosamine] $(98,99)$. $\beta$ - $(1,3)$-D-glucan serves as a backbone structure to which other structures are covalently bound such as $\mathrm{N}$ - and O-linked oligosaccharides, GPI anchored glycoproteins, and $\beta$ - $(1,6)$-glucans forming a mesh of $\beta$-(1,3)-D-glucans sandwiched between inner chitin layer and outer mannan layer $(27,98) . \beta$-(1,3)-D-glucans (hereon referred to as $\beta$-glucans) have been shown to have 
immunomodulatory activities, for instance anti-tumor effects by promoting leukocyte cytotoxic activities and hematopoiesis recovery after chemotherapy, protective effects against bacterial infections and wound healing (100). However, $\beta$-glucans have also been shown to have negative effects, including inducing formation of granulomas, triggering arthritis (101), and are implicated in airway inflammatory responses in human and animal models (102).

In humans, exposure to $\beta$-glucans has been associated with reduced $\mathrm{FEV}_{1}$ /pulmonary function (103), however, the same group found no or even opposite association in later studies (104). Epidemiological studies evaluating multiple parameters, including atopy, lung function $\mathrm{FEV}_{1}$, skin symptoms, inflammation, and cytokines, generally found very few significant associations with exposure to $\beta$-glucan which confirms inconsistency in the results (105). Subjects with previous history of airway reactivity showed minor nose and throat irritation, but no effects on $\mathrm{FEV}_{1}$ or airway responsiveness when challenged with aerosolized $\beta$-glucan (curdlan) $(104,106)$. In healthy volunteers, inhalation of low doses of soluble $\beta$-glucan (grifolan) showed decrease in TNF- $\alpha$ from PBMCs, but no effects on several markers of inflammation and pulmonary function (104). Human dectin-1 activation can enhance or inhibit Th2 polarization depending on the antigen presenting cell encountering $\beta$-glucan in vitro (107). A recent study reported that stimulation of plasmacytoid DCs promote Th2 polarization of naive T cells in vitro in a dectin-1-dependent manner, whereas stimulation of monocyte-derived DCs suppressed Th2 polarization and favored Th17 responses in vitro (107). Other studies have also supported the role of dectin- 1 promoting Th2 polarization of naive $\mathrm{T}$ cells in vitro, by showing that $\beta$-glucans derived from HDM promoted secretion of Th2 type cytokines IL- 4 and IL- 13 by human DCs and CCL20 production by human bronchial epithelial cells, a chemokine associated with Th2 type immune response $(64,108,109)$.

In animal models, $\beta$-glucans purified from various sources have been shown to contribute to allergic airway inflammation, mainly acting as adjuvants when topically co-administered with allergens (102, 110-114). A recent study showed that particulate $\beta$-glucans acted as mucosal adjuvants to HDM allergen when co-administered during priming phase and promoted a strong Th2 allergic airway response to HDM allergen (112). This is consistent with other studies that have shown adjuvant potential of $\beta$-glucans (derived from barley and baker's yeast and C. albicans) when co-administered with ovalbumin (OVA), promoting OVA-specific IgE, eosinophilia, and Th2 cytokines $(110,115)$. In these studies, dectin-1 either had no role in the adjuvant effects of $\beta$-glucans to HDM/OVA allergens or was not investigated $(110,112,115)$. Dectin-1 has also been shown to regulate allergic asthma induced by fungal species depending on the surface exposure of $\beta$-glucans. In $A$. versicolor live conidiainduced asthma, dectin-1-deficient mice showed increased Th2 type allergic airway inflammation with increased IL-33, airway hyperresponsiveness, and reduced IL-17A (116). In the same study, C. cladosporioides live conidia-induced Th2 type, eosinophilic airway inflammation in a dectin-1-independent manner. Subsequent studies showed that the difference in $\beta$-glucan surface exposure between $A$. versicolor and C. cladosporioides was key in the distinct allergic airway profile and that dectin-1 suppressed this Th2 type allergic asthma by promoting IL-17A and IL-22 type immune responses $(116,117)$. In A. fumigatus live conidia allergic asthma chronic model, dectin-1 was shown to promote IL-22 and immunopathology, corroborating other findings showing a detrimental role of dectin-1 in fungalinduced allergic asthma (118). This type of allergic asthma is often seen in allergic models with neutrophilic inflammation that is usually unresponsive to high doses of corticosteroids (111, 119).

Some studies using HDM extracts to induce allergic asthma in animal models show requirement for dectin-1 signaling in Th2 type, eosinophilic, allergic airway asthma $(109,120)$. Dectin-1 is mainly expressed by CD11b DCs and recognizes HDM-derived $\beta$-glucan-like substance to initiate a Th2 polarization and migration of lung DCs to MLN by secretion of chemokines, such as CCL3 and CCR7 (120). Mechanistically, during HDM-induced allergic asthma, dectin-1 induces the production of prostaglandin E2 $\left(\mathrm{PGE}_{2}\right)$, which promotes M2 macrophage polarization and subsequently, Th2 type allergic asthma (121). It is difficult to reconcile studies using HDM extracts, co-administration of $\beta$-glucans with allergens and those using fungal species. The main challenge with commercial HDM extracts is that it is still unclear if $\beta$-glucans are contaminants derived from ingestion of fungi by mites or endosymbionts-derived molecules. Furthermore, commercial HDM extracts do vary largely in their content of these microbial PAMPs from batch to batch depending on preparation (122).

There are considerable inconsistencies in the results using $\beta$-glucans in both human and animal models as discussed above. The disparities could be due to the fact that differences in $\beta$-glucan source, content, solubility, conformation, choice, and strain of animal used, and whether human volunteers had previous fungal exposure, as discussed above. Possible clarification for such inconsistencies using $\beta$-glucan stems from a study, where it was shown that dectin-1 activation requires receptor clustering forming a "phagocytic synapse" (123). In this study, it was demonstrated that larger particulate $\beta$-glucans particles had greater ability to induce this dectin-1 phagocytic synapse (123). It is now easier to explain why $\beta$-glucan exposure has resulted in different phenotypes. Future studies on the effects of $\beta$-glucan in asthma or any other immunomodulatory activities should certainly consider the particulate size of $\beta$-glucan to induce the dectin-1 phagocytic synapse. In summary, it is clear from both animal and mouse studies that much needs to be reconciled on the role of dectin- 1 and its ligand $\beta$-glucans in allergic asthma. Already a few SNPs have been identified in human dectin-1 gene (CLEC7A) which correlates with development of allergic asthma, highlighting the importance of this receptor in driving allergic asthma (124).

\section{CONCLUDING REMARKS}

It is becoming clear that fungal sensitization and fungal-associated components play a crucial role in the initiation, exacerbation, and severity of asthma. Evidence is now emerging showing that CLRs that recognize most fungal-derived components 
are also crucial in shaping the development of allergic asthma. Many other fungal species, such as A. alternate, associated with allergic asthma have not been investigated in CLRs-deficient animals and the ligands and mechanisms of action remain elusive. Of significant interest is how some of these CLRs can be targeted as mucosal adjuvants in cases, where they play protective roles in asthma and drug targets, where they promote allergic asthma, especially difficult to treat asthma. The fact that CLRs can also collaborate with each other or other PRRs is likely to have huge implications in deciphering an already heterogeneous and complex disease like asthma. There is still a lot to be learnt about these interactions and how such collaborations can be used to harness a beneficial immune response toward pathogens or treatment strategies for asthma. Although there is correlation between human and mouse data, there is still a considerable discrepancy in findings using CLR-deficient mice in allergic asthma models and in vitro data using human cells. CLRs-deficient animals are a useful tool in understanding disease mechanisms and this requires improvements to better mimic human asthma. Technologies like humanized mice or

\section{REFERENCES}

1. Anderson GP. Endotyping asthma: new insights into key pathogenic mechanisms in a complex, heterogeneous disease. Lancet (2008) 372:1107-19. doi:10.1016/S0140-6736(08)61452-X

2. Knutsen AP, Bush RK, Demain JG, Denning DW, Dixit A, Fairs A, et al. Fungi and allergic lower respiratory tract diseases. J Allergy Clin Immunol (2012) 129:280-91. doi:10.1016/j.jaci.2011.12.970

3. Denning DW, O'Driscoll BR, Powell G, Chew F, Atherton GT, Vyas A, et al. Randomized controlled trial of oral antifungal treatment for severe asthma with fungal sensitization: the fungal asthma sensitization trial (FAST) study. Am J Respir Crit Care Med (2009) 179:11-8. doi:10.1164/rccm.200805-737OC

4. Agarwal R, Gupta D. Severe asthma and fungi: current evidence. Med Mycol (2011) 49:150-7. doi:10.3109/13693786.2010.504752

5. Harley KG, Macher JM, Lipsett M, Duramad P, Holland NT, Prager SS, et al. Fungi and pollen exposure in the first months of life and risk of early childhood wheezing. Thorax (2009) 64:353-8. doi:10.1136/thx.2007.090241

6. O'Driscoll BR, Hopkinson LC, Denning DW. Mold sensitization is common amongst patients with severe asthma requiring multiple hospital admissions. BMC Pulm Med (2005) 5:4. doi:10.1186/1471-2466-5-4

7. Woodcock A. Moulds and asthma: time for indoor climate change? Thorax (2007) 62:745-6. doi:10.1136/thx.2007.079699

8. Agbetile J, Bourne M, Fairs A, Hargadon B, Desai D, Broad C, et al. Effectiveness of voriconazole in the treatment of Aspergillus fumigatusassociated asthma (EVITA3 study). J Allergy Clin Immunol (2014) 134:33-9. doi:10.1016/j.jaci.2013.09.050

9. Porter PC, Ongeri V, Luong A, Kheradmand F, Corry DB. Seeking common pathophysiology in asthma, atopy and sinusitis. Trends Immunol (2011) 32:43-9. doi:10.1016/j.it.2010.11.007

10. Agarwal R, Nath A, Aggarwal AN, Gupta D, Chakrabarti A. Aspergillus hypersensitivity and allergic bronchopulmonary aspergillosis in patients with acute severe asthma in a respiratory intensive care unit in North India. Mycoses (2010) 53:138-43. doi:10.1111/j.1439-0507.2008.01680.x

11. Denning DW, O'Driscoll BR, Hogaboam CM, Bowyer P, Niven RM. The link between fungi and severe asthma: a summary of the evidence. Eur Respir J (2006) 27:615-26. doi:10.1183/09031936.06.00074705

12. Hartl D, Latzin P, Zissel G, Krane M, Krauss-Etschmann S, Griese M. Chemokines indicate allergic bronchopulmonary aspergillosis in patients with cystic fibrosis. Am J Respir Crit Care Med (2006) 173:1370-6. doi:10.1164/rccm.200508-12710C

13. Fröhlich-Nowoisky J, Pickersgill DA, Després VR, Pöschl U. High diversity of fungi in air particulate matter. Proc Natl Acad Sci U S A (2009) 106:12814-9. doi:10.1073/pnas.0811003106 mice expressing human version of CLRs will give insights into how CLRs shape allergic asthma. Finally, it is clear that some ligands still have ambiguous or unidentified CLRs despite being known for generations to play key roles in allergic asthma, and much work remains to generate new mouse tools to decipher these mysteries.

\section{AUTHOR CONTRIBUTIONS}

This review is submitted as part of Ph.D. thesis by SH. SH incepted, wrote the manuscript. GB and FB edited the manuscript.

\section{FUNDING}

SH studentship was funded by CIDRI (Wellcome Trust initiative, South Africa) and the University of Aberdeen College studentship. SH is currently funded by Robert Bosch Stiftung Foundation. GB is funded by the Wellcome Trust and Medical Research Council Centre for Medical Mycology at the University of Aberdeen.

14. Pringle A. Asthma and the diversity of fungal spores in air. PLoS Pathog (2013) 9:e1003371. doi:10.1371/journal.ppat.1003371

15. Brown GD. Innate antifungal immunity: the key role of phagocytes. Annu Rev Immunol (2011) 29:1-21. doi:10.1146/annurev-immunol-030409-101229

16. Dambuza IM, Brown GD. C-type lectins in immunity: recent developments. Curr Opin Immunol (2015) 32:21-7. doi:10.1016/j.coi.2014.12.002

17. Portnoy JM, Williams PB, Barnes CS. Innate immune responses to fungal allergens. Curr Allergy Asthma Rep (2016) 16:62. doi:10.1007/s11882-0160643-4

18. Ahrens S, Zelenay S, Sancho D, Hanč P, Kjær S, Feest C, et al. F-actin is an evolutionarily conserved damage-associated molecular pattern recognized by DNGR-1, a receptor for dead cells. Immunity (2012) 36:635-45. doi:10.1016/j.immuni.2012.03.008

19. Rogers NC, Slack EC, Edwards AD, Nolte MA, Schulz O, Schweighoffer E, et al. Syk-dependent cytokine induction by Dectin-1 reveals a novel pattern recognition pathway for C type lectins. Immunity (2005) 22:507-17. doi:10.1016/j.immuni.2005.06.005

20. Gross O, Gewies A, Finger K, Schäfer M, Sparwasser T, Peschel C, et al. Card9 controls a non-TLR signalling pathway for innate anti-fungal immunity. Nature (2006) 442:651-6. doi:10.1038/nature04926

21. Gringhuis SI, den Dunnen J, Litjens M, van der Vlist M, Wevers B, Bruijns SCM, et al. Dectin-1 directs Thelper cell differentiation by controlling noncannonical NK-kB activation through Raf-1 and Syk. Nat Immunol (2009) 10:203-13. doi:10.1038/ni.1692

22. Strasser D, Neumann K, Bergmann H, Marakalala MJ, Guler R, Rojowska A, et al. Syk kinase-coupled C-type lectin receptors engage protein kinase C- $\delta$ to elicit Card9 adaptor-mediated innate immunity. Immunity (2012) 36:32-42. doi:10.1016/j.immuni.2011.11.015

23. Brown GD. Dectin-1: a signalling non-TLR pattern-recognition receptor. Nat Rev Immunol (2006) 6:33-43. doi:10.1038/nri1745

24. Kerrigan AM, Brown GD. Syk-coupled C-type lectins in immunity. Trends Immunol (2011) 32:151-6. doi:10.1016/j.it.2011.01.002

25. Osorio F, Reis e Sousa C. Myeloid C-type lectin receptors in pathogen recognition and host defense. Immunity (2011) 34:651-64. doi:10.1016/j. immuni.2011.05.001

26. Redelinghuys P, Brown GD. Inhibitory C-type lectin receptors in myeloid cells. Immunol Lett (2011) 136:1-12. doi:10.1016/j.imlet.2010.10.005

27. Netea MG, Brown GD, Kullberg BJ, Gow NA. An integrated model of the recognition of Candida albicans by the innate immune system. Nat Rev Microbiol (2008) 6:67-78. doi:10.1038/nrmicro1815

28. Amarsaikhan N, Templeton SP. Co-recognition of $\beta$-glucan and chitin and programming of adaptive immunity to Aspergillus fumigatus. Front Microbiol (2015) 6:344. doi:10.3389/fmicb.2015.00344 
29. Schlosser A, Thomsen T, Moeller JB, Nielsen O, Tornøe I, Mollenhauer J, et al. Characterization of FIBCD1 as an acetyl group-binding receptor that binds chitin. J Immunol (2009) 183:3800-9. doi:10.4049/jimmunol.0901526

30. Cash HL, Whitham CV, Behrendt CL, Hooper LV. Symbiotic bacteria direct expression of an intestinal bactericidal lectin. Science (2006) 313:1126-30. doi:10.1126/science.1127119

31. Da Silva CA, Chalouni C, Williams A, Hartl D, Lee CG, Elias JA. Chitin is a size-dependent regulator of macrophage TNF and IL-10 production. J Immunol (2009) 182:3573-82. doi:10.4049/jimmunol.0802113

32. Wagener J, Malireddi RK, Lenardon MD, Köberle M, Vautier S, MacCallum DM, et al. Fungal chitin dampens inflammation through IL-10 induction mediated by NOD2 and TLR9 activation. PLoS Pathog (2014) 10:e1004050. doi:10.1371/journal.ppat.1004050

33. Van Dyken SJ, Mohapatra A, Nussbaum JC, Molofsky AB, Thornton EE, Ziegler SF, et al. Chitin activates parallel immune modules that direct distinct inflammatory responses via innate lymphoid type 2 and $\gamma \delta \mathrm{T}$ cells. Immunity (2014) 40:414-24. doi:10.1016/j.immuni.2014.02.003

34. O’Dea EM, Amarsaikhan N, Li H, Downey J, Steele E, Van Dyken SJ, et al. Eosinophils are recruited in response to chitin exposure and enhance Th2-mediated immune pathology in Aspergillus fumigatus infection. Infect Immun (2014) 82:3199-205. doi:10.1128/IAI.01990-14

35. Van Dyken SJ, Garcia D, Porter P, Huang X, Quinlan PJ, Blanc PD, et al. Fungal chitin from asthma-associated home environments induces eosinophilic lung infiltration. J Immunol (2011) 187:2261-7. doi:10.4049/jimmunol. 1100972

36. Reese TA, Liang HE, Tager AM, Luster AD, Van Rooijen N, Voehringer D, et al. Chitin induces accumulation in tissue of innate immune cells associated with allergy. Nature (2007) 447:92-6. doi:10.1038/nature05746

37. Roy RM, Wüthrich M, Klein BS. Chitin elicits CCL2 from airway epithelial cells and induces CCR2-dependent innate allergic inflammation in the lung. J Immunol (2012) 189:2545-52. doi:10.4049/jimmunol.1200689

38. Van Dyken SJ, Liang HE, Naikawadi RP, Woodruff PG, Wolters PJ, Erle DJ, et al. Spontaneous chitin accumulation in airways and age-related fibrotic lung disease. Cell (2017) 169:497-509. doi:10.1016/j.cell.2017.03.044

39. Kim LK, Morita R, Kobayashi Y, Eisenbarth SC, Lee CG, Elias J, et al. AMCase is a crucial regulator of type 2 immune responses to inhaled house dust mites. Proc Natl Acad Sci U S A (2015) 112:E2891-9. doi:10.1073/pnas.1507393112

40. Vannella KM, Ramalingam TR, Hart KM, de Queiroz Prado R, Sciurba J, Barron L, et al. Acidic chitinase primes the protective immune response to gastrointestinal nematodes. Nat Immunol (2016) 17:538-44. doi:10.1038/ ni. 3417

41. Fitz LJ, DeClercq C, Brooks J, Kuang W, Bates B, Demers D, et al. Acidic mammalian chitinase is not a critical target for allergic airway disease. Am J Respir Cell Mol Biol (2012) 46:71-9. doi:10.1165/rcmb.2011-0095OC

42. Seibold MA, Reese TA, Choudhry S, Salam MT, Beckman K, Eng C, et al. Differential enzymatic activity of common haplotypic versions of the human acidic mammalian chitinase protein. J Biol Chem (2009) 284:19650-8. doi:10.1074/jbc.M109.012443

43. Ariizumi K, Shen GL, Shikano S, Ritter R III, Zukas P, Edelbaum D, et al. Cloning of a second dendritic cell-associated C-type lectin (Dectin-2) and its alternatively spliced isoforms. J Biol Chem (2000) 275:11957-63. doi:10.1074/ jbc.275.16.11957

44. Aragane Y, Maeda A, Schwarz A, Tezuka T, Ariizumi K, Schwarz T. Involvement of Dectin-2 in ultraviolet radiation-induced tolerance. J Immunol (2003) 171:3801-7. doi:10.4049/jimmunol.171.7.3801

45. Robinson MJ, Osorio F, Rosas M, Freitas RP, Schweighoffer E, Gross O, et al. Dectin-2 is a Syk-coupled pattern recognition receptor crucial for Th17 responses to fungal infection. J Exp Med (2009) 206:2037-51. doi:10.1084/ jem. 20082818

46. McGreal EP, Rosas M, Brown GD, Zamze S, Wong SY, Gordon S, et al. The carbohydrate-recognition domain of Dectin-2 is a C-type lectin with specificity for high mannose. Glycobiology (2006) 16:422-30. doi:10.1093/ glycob/cwj077

47. Saijo S, Ikeda S, Yamabe K, Kakuta S, Ishigame H, Akitsu A, et al. Dectin-2 recognition of $\alpha$-mannans and induction of Th17 cell differentiation is essential for host defense against Candida albicans. Immunity (2010) 32:681-91. doi:10.1016/j.immuni.2010.05.001

48. Barrett NA, Maekawa A, Rahman OM, Austen KF, Kanaoka Y. Dectin-2 recognition of house dust mite triggers cysteinyl leukotriene generation by dendritic cells. J Immunol (2009) 182:1119-28. doi:10.4049/jimmunol.182. 2.1119

49. Sato K, Yang X, Yudate T, Chung J, Wu J, Luby-Phelps K, et al. Dectin-2 is a pattern recognition receptor for fungi that couples with the $\mathrm{Fc}$ receptor $\gamma$ chain to induce innate immune responses. J Biol Chem (2006) 281:38854-66. doi:10.1074/jbc.M606542200

50. Gringhuis SI, Wevers BA, Kaptein TM, van Capel TMM, Theelen B, Boekhout T, et al. Selective c-Rel activation via Malt1 controls anti-fungal TH-17 immunity by Dectin-1 and Dectin-2. PLoS Pathog (2011) 7:e1001259. doi:10.1371/journal.ppat.1001259

51. Barrett NA, Austen KF. Innate cells and T helper 2 cell immunity in airway inflammation. Immunity (2009) 31:425-37. doi:10.1016/j.immuni.2009. 08.014

52. Norimoto A, Hirose K, Iwata A, Tamachi T, Yokota M, Takahashi K, et al. Dectin-2 promotes house dust mite-induced T helper type 2 and type 17 cell differentiation and allergic airway inflammation in mice. Am J Respir Cell Mol Biol (2014) 51:201-9. doi:10.1165/rcmb.2013-0522OC

53. Barrett NA, Rahman OM, Fernandez JM, Parsons MW, Xing W, Austen KF, et al. Dectin-2 mediates Th2 immunity through the generation of cysteinyl leukotrienes. J Exp Med (2011) 208:593-604. doi:10.1084/jem.20100793

54. Clarke DL, Davis NH, Campion CL, Foster ML, Heasman SC, Lewis AR, et al. Dectin-2 sensing of house dust mite is critical for the initiation of airway inflammation. Mucosal Immunol (2014) 7:558-67. doi:10.1038/mi. 2013.74

55. Parsons MW, Li L, Wallace AM, Lee MJ, Katz HR, Fernandez JM, et al. Dectin-2 regulates the effector phase of house dust mite-elicited pulmonary inflammation independently from its role in sensitization. J Immunol (2014) 192:1361-71. doi:10.4049/jimmunol.1301809

56. Tjota MY, Hrusch CL, Blaine KM, Williams JW, Barrett NA, Sperling AI. Signaling through $\mathrm{FcR} \gamma$-associated receptors on dendritic cells drives IL-33dependent TH2-type responses. J Allergy Clin Immunol (2014) 134:706-13. e8. doi:10.1016/j.jaci.2014.06.013

57. LeeMJ, YoshimotoE, SaijoS, IwakuraY,LinX,KatzHR, etal.Phosphoinositide 3-kinase $\delta$ regulates Dectin-2 signaling and the generation of Th2 and Th17 immunity. J Immunol (2016) 197:278-87. doi:10.4049/jimmunol. 1502485

58. Geijtenbeek TBH, Gringhuis SI. Signalling through C-type lectin receptors: shaping immune responses. Nat Rev Immunol (2009) 9:465-79. doi:10.1038/ nri2569

59. Garcia-Vallejo JJ, van Kooyk Y. The physiological role of DC-SIGN: a tale of mice and men. Trends Immunol (2013) 34:482-6. doi:10.1016/j.it.2013.03.001

60. Gringhuis SI, den Dunnen J, Litjens M, van der Vlist M, Geijtenbeek TBH. Carbohydrate-specific signaling through the DC-SIGN signalosome tailors immunity to Mycobacterium tuberculosis, HIV-1 and Helicobacter pylori. Nat Immunol (2009) 10:1081-8. doi:10.1038/ni.1778

61. Gringhuis SI, den Dunnen J, Litjens M, van het Hof B, van Kooyk Y, Geijtenbeek TBH. C-type lectin DC-SIGN modulates toll-like receptor signaling via Raf-1 kinase-dependent acetylation of transcription factor NF- $\mathrm{kB}$. Immunity (2007) 26:605-16. doi:10.1016/j.immuni.2007.03.012

62. Kaptein TM, Wevers BA, Mesman AW, Gringhuis SI, Geijtenbeek TBH. Fucose-specific DC-SIGN signalling directs T helper cell type-2 responses via IKKe- and CYLD-dependent Bcl3 activation. Nat Commun (2014) 5:1-13. doi:10.1038/ncomms 4898

63. Emara M, Royer PJ, Mahdavi J, Shakib F, Ghaemmaghami AM. Retagging identifies dendritic cell-specific intercellular adhesion molecule-3 (ICAM3)grabbing non-integrin (DC-SIGN) protein as a novel receptor for a major allergen from house dust mite. J Biol Chem (2012) 287:5756-63. doi:10.1074/ jbc.M111.312520

64. Shreffler WG, Castro RR, Kucuk ZY, Charlop-Powers Z, Grishina G, Yoo $\mathrm{S}$, et al. The major glycoprotein allergen from Arachis hypogaea, Ara h 1, is a ligand of dendritic cell-specific ICAM-grabbing nonintegrin and acts as a Th2 adjuvant in vitro. JImmunol (2006) 177:3677-85. doi:10.4049/ jimmunol.177.6.3677

65. Hsu SC, Chen CH, Tsai SH, Kawasaki H, Hung CH, Chu YT, et al. Functional interaction of common allergens and a C-type lectin receptor, dendritic cell-specific ICAM3-grabbing non-integrin (DC-SIGN), on human dendritic cells. J Biol Chem (2010) 285:7903-10. doi:10.1074/jbc.M109.058370

66. Huang H-J, Lin Y-L, Liu C-F, Kao H-F, Wang J-Y. Mite allergen decreases DC-SIGN expression and modulates human dendritic cell differentiation and 
function in allergic asthma. Mucosal Immunol (2011) 4:519-27. doi:10.1038/ mi.2011.17

67. Furmonaviciene R, Ghaemmaghami AM, Boyd SE, Jones NS, Bailey K, Willis AC, et al. The protease allergen Der $\mathrm{p} 1$ cleaves cell surface DC-SIGN and DC-SIGNR: experimental analysis of in silico substrate identification and implications in allergic responses. Clin Exp Allergy (2007) 37:231-42. doi:10.1111/j.1365-2222.2007.02651.x

68. Taylor PR, Gordon S, Martinez-Pomares L. The mannose receptor: linking homeostasis and immunity through sugar recognition. Trends Immunol (2005) 26:104-10. doi:10.1016/j.it.2004.12.001

69. Stahl P, Gordon S. Expression of a mannosyl-fucosyl receptor for endocytosis on cultured primary macrophages and their hybrids. J Cell Biol (1982) 93:49-56. doi:10.1083/jcb.93.1.49

70. Taylor ME, Conary JT, Lennartz MR, Stahl PD, Drickamer K. Primary structure of the mannose receptor contains multiple motifs resembling carbohydrate-recognition domains. J Biol Chem (1990) 265:12156-62.

71. Maródi L, Korchak HM, Johnston RB. Mechanisms of host defense against Candida species. I. Phagocytosis by monocytes and monocyte-derived macrophages. J Immunol (1991) 146:2783-9.

72. Ezekowitz RA, Williams DJ, Koziel H, Armstrong MY, Warner A, Richards FF, et al. Uptake of Pneumocystis carinii mediated by the macrophage mannose receptor. Nature (1991) 351:155. doi:10.1038/351155a0

73. Nguyen DG, Hildreth JEK. Involvement of macrophage mannose receptor in the binding and transmission of HIV by macrophages. Eur J Immunol (2003) 33:483-93. doi:10.1002/immu.200310024

74. Rajaram MVS, Arnett E, Azad AK, Guirado E, Ni B, Gerberick AD, et al. M. tuberculosis-initiated human mannose receptor signaling regulates macrophage recognition and vesicle trafficking by FcR g-chain, Grb2, and SHP-1. Cell Rep (2017) 21:126-40. doi:10.1016/j.celrep.2017.09.034

75. Taylor PR, Zamze S, Stillion RJ, Wong SY, Gordon S, Martinez-Pomares L. Development of a specific system for targeting protein to metallophilic macrophages. Proc Natl Acad Sci U S A (2004) 101:1963-8. doi:10.1073/ pnas. 0308490100

76. Royer PJ, Emara M, Yang C, Al-Ghouleh A, Tighe P, Jones N, et al. The mannose receptor mediates the uptake of diverse native allergens by dendritic cells and determines allergen-induced $\mathrm{T}$ cell polarization through modulation of IDO activity. J Immunol (2010) 185:1522-31. doi:10.4049/ jimmunol.1000774

77. Emara M, Royer PJ, Abbas Z, Sewell HF, Mohamed GG, Singh S, et al. Recognition of the major cat allergen Fel d 1 through the cysteine-rich domain of the mannose receptor determines its allergenicity. J Biol Chem (2011) 286:13033-40. doi:10.1074/jbc.M111.220657

78. Al-Ghouleh A, Johal R, Sharquie IK, Emara M, Harrington H, Shakib F, et al. The glycosylation pattern of common allergens: the recognition and uptake of Der $\mathrm{p} 1$ by epithelial and dendritic cells is carbohydrate dependent. PLoS One (2012) 7:e33929. doi:10.1371/journal.pone.0033929

79. Zhou Y, Do DC, Ishmael FT, Squadrito ML, Man H, Ms T, et al. Mannose receptor modulates macrophage polarization and allergic inflammation through. JAllergy Clin Immunol (2017) 141(1):350-64.e8. doi:10.1016/j. jaci.2017.04.049

80. Kishore U, Greenhough TJ, Waters P, Shrive AK, Ghai R, Kamran MF, et al. Surfactant proteins SP-A and SP-D: structure, function and receptors. Mol Immunol (2006) 43:1293-315. doi:10.1016/j.molimm. 2005.08.004

81. Salazar F, Ghaemmaghami AM. Allergen recognition by innate immune cells: critical role of dendritic and epithelial cells. Front Immunol (2013) 4:356. doi:10.3389/fimmu.2013.00356

82. Wang JY, Kishore U, Lim BL, Strong P, Reid KB. Interaction of human lung surfactant proteins A and D with mite (Dermatophagoides pteronyssinus) allergens. Clin Exp Immunol (1996) 106:367-73. doi:10.1046/j.1365-2249.1996. d01-838.x

83. Madan T, Kaur S, Saxena S, Singh M, Kishore U, Thiel S, et al. Role of collectins in innate immunity against aspergillosis. Med Mycol (2005) 43(Suppl 1):S155-63. doi:10.1080/13693780500088408

84. Madan T, Kishore U, Shah A, Eggleton P, Strong P, Wang JY, et al. Lung surfactant proteins $\mathrm{A}$ and $\mathrm{D}$ can inhibit specific IgE binding to the allergens of Aspergillus fumigatus and block allergen-induced histamine release from human basophils. Clin Exp Immunol (1997) 110:241-9. doi:10.1111/ j.1365-2249.1997.tb08323.x
85. Qaseem AS, Singh I, Pathan AA, Layhadi JA, Parkin R, Alexandra F, et al. A recombinant fragment of human surfactant protein D suppresses basophil activation and T-Helper type 2 and B-cell responses in grass pollen-induced allergic inflammation. Am J Respir Crit Care Med (2017) 196:1526-34. doi:10.1164/rccm.201701-0225OC

86. Madan T, Reid KBM, Singh M, Sarma PU, Kishore U. Susceptibility of mice genetically deficient in the surfactant protein (SP)-A or SP-D gene to pulmonary hypersensitivity induced by antigens and allergens of Aspergillus fumigatus. J Immunol (2005) 174:6943-54. doi:10.4049/jimmunol.174. 11.6943

87. Minutti CM, Jackson-Jones LH, García-Fojeda B, Knipper JA, Sutherland TE, Logan N, et al. Local amplifiers of IL-4R $\alpha$-mediated macrophage activation promote repair in lung and liver. Science (2017) 356:1076-80. doi:10.1126/ science.aaj2067

88. Saxena S, Madan T, Shah A, Muralidhar K, Sarma PU. Association of polymorphisms in the collagen region of SP-A2 with increased levels of total IgE antibodies and eosinophilia in patients with allergic bronchopulmonary aspergillosis. J Allergy Clin Immunol (2003) 111:1001-7. doi:10.1067/ mai.2003.1395

89. Ariizumi K, Shen GL, Shikano S, Xu S, Ritter R III, Kumamoto T, et al. Identification of a novel, dendritic cell-associated molecule, Dectin-1, by subtractive cDNA cloning. J Biol Chem (2000) 275:20157-67. doi:10.1074/ jbc.M909512199

90. Brown GD, Gordon S. Immune recognition. A new receptor for beta-glucans. Nature (2001) 413:36-7. doi:10.1038/35092620

91. Means TK, Mylonakis E, Tampakakis E, Colvin RA, Seung E, Puckett L, et al. Evolutionarily conserved recognition and innate immunity to fungal pathogens by the scavenger receptors SCARF1 and CD36. J Exp Med (2009) 206:637-53. doi:10.1084/jem.20082109

92. Swidergall M, Solis NV, Lionakis MS, Filler SG. EphA2 is an epithelial cell pattern recognition receptor for fungal $\beta$-glucans. Nat Microbiol (2018) 3:53-61. doi:10.1038/s41564-017-0059-5

93. Palma AS, Feizi T, Zhang Y, Stoll MS, Lawson AM, Díaz-Rodríguez E, et al. Ligands for the $\beta$-glucan receptor, Dectin-1, assigned using 'designer' microarrays of oligosaccharide probes (neoglycolipids) generated from glucan polysaccharides. J Biol Chem (2006) 281:5771-9. doi:10.1074/jbc. M511461200

94. Brown GD, Gordon S. Fungal beta-glucans and mammalian immunity. Immunity (2003) 19:311-5. doi:10.1016/S1074-7613(03)00233-4

95. Saijo S, Fujikado N, Furuta T, Chung SH, Kotaki H, Seki K, et al. Dectin-1 is required for host defense against Pneumocystis carinii but not against Candida albicans. Nat Immunol (2007) 8:39-46. doi:10.1038/ni1425

96. Taylor PR, Tsoni SV, Willment JA, Dennehy KM, Rosas M, Findon H, et al. Dectin-1 is required for beta-glucan recognition and control of fungal infection. Nat Immunol (2007) 8:31-8. doi:10.1038/ni1408

97. Williams DL, McNamee RB, Jones EL, Pretus HA, Ensley HE, Browder IW, et al. A method for the solubilization of a $(1--3)$-beta-D-glucan isolated from Saccharomyces cerevisiae. Carbohydr Res (1991) 219:203-13. doi:10.1016/0008-6215(91)89052-H

98. Bowman SM, Free SJ. The structure and synthesis of the fungal cell wall. Bioessays (2006) 28:799-808. doi:10.1002/bies.20441

99. Klis FM, De Groot P, Hellingwerf K. Molecular organization of the cell wall of Candida albicans. Med Mycol (2001) 39:1-8. doi:10.1080/mmy.39.1.1.8-0

100. Tsoni SV, Brown GD. $\beta$-Glucans and Dectin-1. Ann N Y Acad Sci (2008) 1143:45-60. doi:10.1196/annals.1443.019

101. Yoshitomi H, Sakaguchi N, Kobayashi K, Brown GD, Tagami T, Sakihama T, et al. A role for fungal $\beta$-glucans and their receptor Dectin- 1 in the induction of autoimmune arthritis in genetically susceptible mice. J Exp Med (2005) 201:949-60. doi:10.1084/jem.20041758

102. Fogelmark B, Sjöstrand M, Rylander R. Pulmonary inflammation induced by repeated inhalations of beta(1,3)-D-glucan and endotoxin. Int J Exp Pathol (1994) 75:85-90.

103. Thorn J, Rylander R. Airways inflammation and glucan in a rowhouse area. Am J Respir Crit Care Med (1998) 157:1798-803. doi:10.1164/ajrccm.157.6.9706081

104. Beijer L, Rylander R. ( $1 \rightarrow 3)-\beta$-D-Glucan does not induce acute inflammation after nasal deposition. Mediators Inflamm (2005) 2005:50-2. doi:10.1155/ MI.2005.50

105. Simpson JL, Brooks C, Douwes J. Innate immunity in asthma. Paediatr Respir $\operatorname{Rev}(2008)$ 9:263-70. doi:10.1016/j.prrv.2008.05.007 
106. Rylander R. Airway responsiveness and chest symptoms after inhalation of endotoxin or (1-3)-B-D- Glucan. Indoor Built Environ (1996) 5:106-11. doi:10.1177/1420326X9600500206

107. Joo H, Upchurch K, Zhang W, Ni L, Li D, Xue Y, et al. Opposing roles of Dectin-1 expressed on human plasmacytoid dendritic cells and myeloid dendritic cells in Th2 polarization. J Immunol (2015) 195:1723-31. doi:10.4049/ jimmunol.1402276

108. Nathan AT, Peterson EA, Chakir J, Wills-Karp M. Innate immune responses of airway epithelium to house dust mite are mediated through $\beta$-glucandependent pathways. J Allergy Clin Immunol (2009) 123:612-8. doi:10.1016/j. jaci.2008.12.006

109. Ryu JH, Yoo JY, Kim MJ, Hwang SG, Ahn KC, Ryu JC, et al. Distinct TLRmediated pathways regulate house dust mite-induced allergic disease in the upper and lower airways. J Allergy Clin Immunol (2013) 131:549-61. doi:10.1016/j.jaci.2012.07.050

110. Inoue K, Takano H, Koike E, Yanagisawa R, Oda T, Tamura H, et al. Candida soluble cell wall beta-glucan facilitates ovalbumin-induced allergic airway inflammation in mice: possible role of antigen-presenting cells. Respir Res (2009) 10:68. doi:10.1186/1465-9921-10-68

111. Hadebe S, Kirstein F, Fierens K, Chen K, Drummond RA, Vautier $\mathrm{S}$, et al. Microbial ligand costimulation drives neutrophilic steroidrefractory asthma. PLoS One (2015) 10:1-17. doi:10.1371/journal.pone. 0137945

112. Hadebe S, Kirstein F, Fierens K, Redelinghuys P, Murray GI, Williams DL, et al. $\beta$-Glucan exacerbates allergic airway responses to house dust mite allergen. Respir Res (2016) 17:35. doi:10.1186/s12931-016-0352-5

113. Fogelmark B, Thorn J, Rylander R. Inhalation of (1-3)- $\beta$-D-glucan causes airway eosinophilia. Mediators Inflamm (2001) 10(1):13-9. doi:10.1080/09629350123707

114. Carter RW, Thompson C, Reid DM, Wong SYC, Tough DF. Preferential induction of $\mathrm{CD} 4+\mathrm{T}$ cell responses through in vivo targeting of antigen to dendritic cell-associated C-type lectin-1. J Immunol (2006) 177:2276-84. doi:10.4049/jimmunol.177.4.2276

115. Instanes C, Ormstad H, Rydjord B, Wiker HG, Hetland G. Mould extracts increase the allergic response to ovalbumin in mice. Clin Exp Allergy (2004) 34:1634-41. doi:10.1111/j.1365-2222.2004.02076.x

116. Mintz-Cole RA, Gibson AM, Bass SA, Budelsky AL, Reponen T, Hershey GKK. Dectin-1 and IL-17A suppress murine asthma induced by Aspergillus versicolor but not Cladosporium cladosporioides due to differences in $\beta$-glucan surface exposure. J Immunol (2012) 189:3609-17. doi:10.4049/ jimmunol.1200589

117. Mintz-Cole RA, Brandt EB, Bass SA, Gibson AM, Reponen T, Khurana Hershey GK. Surface availability of beta-glucans is critical determinant of host immune response to Cladosporium cladosporioides. J Allergy Clin Immunol (2013) 132:159-69. doi:10.1016/j.jaci.2013.01.003

118. Lilly LM, Gessner MA, Dunaway CW, Metz AE, Schwiebert L, Weaver CT, et al. The $\beta$-glucan receptor Dectin-1 promotes lung immunopathology during fungal allergy via IL-22. J Immunol (2012) 189:3653-60. doi:10.4049/ jimmunol.1201797

119. Zhang Z, Biagini Myers JM, Brandt EB, Ryan PH, Lindsey M, Mintz-Cole RA, et al. $\beta$-Glucan exacerbates allergic asthma independent of fungal sensitization and promotes steroid-resistant TH2/TH17 responses. J Allergy Clin Immunol (2017) 139:54-65.e8. doi:10.1016/j.jaci.2016.02.031

120. Ito T, Hirose K, Norimoto A, Tamachi T, Yokota M, Saku A, et al. Dectin-1 plays an important role in house dust mite-induced allergic airway inflammation through the activation of CD11b+ dendritic cells. J Immunol (2017) 198:61-70. doi:10.4049/jimmunol.1502393

121. Ito T, Hirose K, Norimoto A, Saku A, Nakajima H. Dectin-1 plays a critical role in HDM-induced PGE2 production in macrophages. Allergol Int (2017) 66:S44-6. doi:10.1016/j.alit.2017.05.001

122. Post S, Nawijn MC, Hackett TL, Baranowska M, Gras R, van Oosterhout AJ, et al. The composition of house dust mite is critical for mucosal barrier dysfunction and allergic sensitisation. Thorax (2012) 67:488-95. doi:10.1136/ thoraxjnl-2011-200606

123. Goodridge HS, Reyes CN, Becker CA, Katsumoto TR, Ma J, Wolf AJ, et al. Activation of the innate immune receptor Dectin-1 upon formation of a "phagocytic synapse". Nature (2011) 472:471-5. doi:10.1038/nature10071

124. Overton NL, Simpson A, Bowyer P, Denning DW. Genetic susceptibility to severe asthma with fungal sensitization. Int J Immunogenet (2017) 44:93-106. doi:10.1111/iji.12312

125. Madan T, Kishore U, Singh M, Strong P, Clark H, Hussain EM, et al. Surfactant proteins A and D protect mice against pulmonary hypersensitivity induced by Aspergillus fumigatus antigens and allergens. J Clin Invest (2001) 107:467-75. doi:10.1172/JCI10124

Conflict of Interest Statement: The authors declare that the research was conducted in the absence of any commercial or financial relationships that could be construed as a potential conflict of interest.

Copyright (c) 2018 Hadebe, Brombacher and Brown. This is an open-access article distributed under the terms of the Creative Commons Attribution License (CC BY). The use, distribution or reproduction in other forums is permitted, provided the original author(s) and the copyright owner are credited and that the original publication in this journal is cited, in accordance with accepted academic practice. No use, distribution or reproduction is permitted which does not comply with these terms. 